\title{
Hydrogen-rich Syngas Production via Catalytic Gasification of Biomass Using Ni/Zr-MOF Catalyst
}

Shuang Shang, Zhenhua Qin, Kui Lan, Yan Wang, Juanjuan Zhang, Tao Xiong, Weitao He, and Jianfen $\mathrm{Li} *$

A Ni/Zr-MOF catalyst supported on Zr-metal organic framework (Zr-MOF) was prepared by a homogeneous precipitation method and was used in the co-gasification of wet sludge and straw. The Ni/Zr-MOF catalyst was characterized via thermogravimetric, X-ray diffraction, scanning electron microscopy, energy dispersive spectrometry, and Brunauer-Emmett-Teller analyses. The experimental results illustrated that the Zr-MOF crystals were an octahedral structure with a specific surface area of $806 \mathrm{~m}^{2} / \mathrm{g}$, and had mesoporous structure. Nickel was uniformly dispersed on the surface of the catalyst, and most of the Ni/Zr-MOF crystals maintained an octahedral morphology. Compared with non-catalyst biomass gasification, the $\mathrm{H}_{2}$ yield increased from $0.39 \mathrm{~mol} / \mathrm{kg}$ to $11.87 \mathrm{~mol} / \mathrm{kg}$ using the $\mathrm{Ni} / \mathrm{Zr}$ MOF catalyst at $500^{\circ} \mathrm{C}$. After 10 instances of reuse, the $\mathrm{H}_{2}$ yield was still as high as $10.11 \mathrm{~mol} / \mathrm{kg}$. The Ni/Zr-MOF catalyst exhibited high catalytic activity and stability for biomass gasification at low-temperature.

Keywords: Gasification; Biomass; Zr-MOF; Catalyst; Syngas

Contact information: School of Chemical and Environmental Engineering, Wuhan Polytechnic University, Wuhan 430023, China; *Corresponding author: lijfen@163.com

\section{INTRODUCTION}

Energy and environment issues are current topics of concern in society. With the rapid development of the economy, fossil fuels, as non-renewable sources of energy, have been unable to meet the growing demand for energy. Long-term development and use of fossil energy will face the problem of fuel depletion, and oil reserves are estimated to be depleted by 2050 (Saxena et al. 2009). Biomass is a renewable material that can be converted into solid, liquid, and gaseous fuels through chemical processes (Guan et al. 2016). Biomass pyrolysis or gasification is one of the most effective ways to convert biomass into fuel (Ismail and El-Salam 2017). Pyrolysis can make full use of biomass raw materials. The products are gas, tar, and char, and the process does not form toxic and harmful organic compounds (Xu et al. 2017). The problem with pyrolysis is its low content of flammable gases in the product gas, such as $\mathrm{H}_{2}$ and $\mathrm{CO}$. Additionally, a large amount of tar in the gas phase will condense at low temperatures, blocking the downstream pipeline of the process. In addition, tar can cause a lot of energy loss and some environmental problems related to tar (Han and Kim 2008). Catalytic cracking has high cracking tar efficiency and gas reforming ability. Converting tar into useful syngas is a technically feasible and economical gas purification technology (Zhou et al. 2017).

Ni-based catalysts have attracted much attention for tar cracking and gas purification due to their high catalytic activity and relatively low cost. Some studies also show that Ni-based catalysts can reverse ammonia reaction; thus, it is possible to reduce $\mathrm{NO}_{\mathrm{x}}$ emission during biomass gasification and tar reforming (Shen and Yoshikawa 2013). 
The traditional Ni-based catalyst supports are mainly metal oxide $\left(\gamma-\mathrm{Al}_{2} \mathrm{O}_{3}, \mathrm{CeO}_{2}\right.$, and $\mathrm{MgO}$ ) and natural materials (palygorskite, dolomite, and olivine). The accommodation of $\mathrm{Ni}$ in the support could improve Ni dispersion, suppress the aggregation of metal particles, and control the particle size efficiently (Zhang et al. 2018).

In recent years, char has also been used as the support for Ni-based catalysts due to its pore structure and large specific surface area. Hu et al. (2018) prepared Ni/char catalysts using pine sawdust char as the catalyst support. The results showed that the char-supported nickel catalysts had high catalytic activity in biomass gasification and tar removal. Shen $e t$ al. (2014) prepared a Ni-Fe/RHC catalyst using rice husk char (RHC) as the support. It was found that rice husk char can be prepared as a highly porous carbonaceous material, like activated char. The support with a larger specific surface area can promote the dispersion of metal elements on the surface of the catalyst; at the same time, a larger pore size is beneficial to the diffusion of reactants and products in the channel of the catalyst. Xie et al. (2018) used carbon nanofiber (CNF) as the catalyst support to prepare an $\mathrm{Fe}-\mathrm{Ni} / \mathrm{CNF}$ catalyst and applied it to the catalytic conversion of tar from biomass gasification. The experimental results indicated that the Brunauer-Emmett-Teller (BET) surface area and average pore diameter of $\mathrm{Fe}-\mathrm{Ni} / \mathrm{CNF}$ was $283 \mathrm{~m}^{2} / \mathrm{g}$ and $3.73 \mathrm{~nm}$, respectively. The syngas yield increased from 0.3 to $0.7 \mathrm{~L} / \mathrm{g}$ using an $\mathrm{Fe}-\mathrm{Ni} / \mathrm{CNF}$ catalyst. For the same metal loading, a support with a larger specific surface area can provide more active sites, and the catalytic activity of the resulting catalyst is higher. Therefore, to improve the catalytic activity of catalysts, researchers have prepared many synthetic materials with high specific areas, such as SBA-15, ZSM-5, MCM-41, etc. Zhang et al. (2019) prepared $\mathrm{Ni} / \mathrm{Al}_{2} \mathrm{O}_{3}$ and Ni/SBA-15 catalysts with $20 \%$ nickel loading using $\mathrm{Al}_{2} \mathrm{O}_{3}$ and SBA-15 as a support to compare the effect of support on catalytic activity. The results showed that the BET surface area of Ni/SBA-15 $\left(333.1 \mathrm{~m}^{2} / \mathrm{g}\right)$ was higher than that of $\mathrm{Ni}_{1} \mathrm{Al}_{2} \mathrm{O}_{3}(139.9 \mathrm{~m} / \mathrm{g})$, and the $\mathrm{Ni} / \mathrm{SBA}-15$ catalyst showed superior activity to that of the $\mathrm{Ni} / \mathrm{Al}_{2} \mathrm{O}_{3}$ catalyst. Wu et al. (2011) prepared Ni/MCM-41 catalysts using MCM-41 as support for sawdust gasification to produce hydrogen. The results showed that Ni/MCM-41 catalysts had higher specific surface areas $\left(>737 \mathrm{~m}^{2} / \mathrm{g}\right)$, and the $\mathrm{NiO}$ particles had good dispersion on the surface of the support.

The Zr-metal organic framework (Zr-MOF) material has an octahedral structure, and its specific surface area could reach $1367 \mathrm{~m}^{2} / \mathrm{g}$ (Ren et al. 2014). The uniform structure and larger specific surface area of Zr-MOF material enable the metal to be evenly dispersed on the surface of the support, and the rich pore structure can make the tar fully contact with the catalyst. In addition, presently, Zr-MOF material is mainly used for hydrogen storage, but it has not been used in the study of biomass catalytic gasification for hydrogen production. Therefore, in this work, an Ni/Zr-MOF catalyst was prepared using synthesized $\mathrm{Zr}$-MOF materials as support and applied to the co-gasification of wet sludge and wheat straw.

The Ni/Zr-MOF catalyst was characterized by thermogravimetric (TG), X-ray diffraction (XRD), scanning electron microscopy (SEM), energy dispersive spectrometry (EDS), and BET analyses to explore the mechanism of the catalyst. A series of experiments were performed to explore the effects of the catalyst on the composition and yield of gases, $\mathrm{Ni}$ loading, cycle stability of catalyst and catalyst regeneration. Meanwhile, a non-catalyst was also studied as the baseline for comparison. 


\section{EXPERIMENTAL}

\section{Materials}

The wet sludge used in this study was collected from a domestic sewage treatment plant in Wuhan, Hubei Province, China. The sludge was dried at $105{ }^{\circ} \mathrm{C}$ for $24 \mathrm{~h}$ in an oven to ensure that their mass was constant. The wet sludge with a moisture content of $80 \%$ was obtained by uniformly mixing the dry sludge with a certain amount of water. The wheat straw selected from Wuhan, China was pulverized to the size of $0.3 \mathrm{~mm}$ to $4.0 \mathrm{~mm}$ with a small crusher to eliminate the influence of the particle size on the experimental results. The biomass sample obtained by mixing wheat straw and wet sludge with a moisture content of $80 \%$ was used as the raw material for hydrogen-rich syngas production. The proximate and ultimate analyses of dry sludge and wheat straw are listed in Table 1 and presented on an air-dried basis.

Table 1. Proximate and Ultimate Analysis of Dry Sludge and Wheat Straw

\begin{tabular}{|c|c|c|c|c|c|c|c|c|c|}
\hline \multirow{2}{*}{ Sample } & \multicolumn{4}{|c|}{ Proximate Analysis (wt\%) } & \multicolumn{4}{c|}{ Ultimate Analysis (wt\%) } \\
\cline { 2 - 10 } & $M^{\text {ad }}$ & $A^{\text {ad }}$ & $V^{\text {ad }}$ & $C_{F^{\text {ad }}}$ & $\mathrm{C}$ & $\mathrm{H}$ & $\mathrm{N}$ & $\mathrm{S}$ & $\mathrm{O}^{\mathrm{c}}$ \\
\hline Sludge & 4.15 & 50.69 & 35.33 & 9.83 & 25.20 & 5.62 & 3.82 & 0.15 & 14.52 \\
\hline Wheat Straw & 10.88 & 6.91 & 67.11 & 15.10 & 31.04 & 4.22 & 0.40 & 0.06 & 57.37 \\
\hline
\end{tabular}

M (Moisture); A (Ash); V (Volatile); $C_{F}$ (Fixed carbon); ad Air-dried; ' ${ }^{\mathrm{C}}$ Calculated by difference (O\% $=100 \%-$ Ash $\%-\mathrm{C} \%-\mathrm{H} \%-\mathrm{N} \%-\mathrm{S} \%)$

\section{Methods}

Catalysts preparation

The highly ordered mesoporous Zr-MOF was synthesized by the solvothermal method reported previously (Ren et al. 2014). Approximately $2.34 \mathrm{~g}$ of $\mathrm{ZrCl}_{4}$ and $1.66 \mathrm{~g}$ of terephthalic acid were ultrasonically dissolved in $100 \mathrm{~mL}$ of $\mathrm{N}, \mathrm{N}$-dimethylformamide (DMF) solvent. Approximately $38 \mathrm{~mL}$ of formic acid was added as the modulator. The solution was transferred to a Teflon-lined pressure vessel before being heated up to $120^{\circ} \mathrm{C}$ and maintained at that temperature for $24 \mathrm{~h}$ under static conditions. After cooling, the white product was collected by centrifugation, washed twice with $200 \mathrm{~mL}$ DMF and $200 \mathrm{~mL}$ ethanol, and then dried for $12 \mathrm{~h}$ in an oven at $60{ }^{\circ} \mathrm{C}$.

The Ni/Zr-MOF catalyst was prepared by the homogeneous precipitation method using $\mathrm{Ni}\left(\mathrm{NO}_{3}\right)_{2} \cdot 6 \mathrm{H}_{2} \mathrm{O}$ as the nickel precursor. The nickel loading was $20 \mathrm{wt} \%$. A certain proportion of $\mathrm{Ni}\left(\mathrm{NO}_{3}\right)_{2} \cdot 6 \mathrm{H}_{2} \mathrm{O}$ and $\mathrm{Zr}-\mathrm{MOF}$ material was added in a $500-\mathrm{mL}$ flask. Then, 4 $\mathrm{g}$ of potassium hydroxide as precipitant and $400 \mathrm{~mL}$ of distilled water were added. The blend was stirred at $115^{\circ} \mathrm{C}$ for $3 \mathrm{~h}$ and precipitated for $1 \mathrm{~h}$. After filtering and drying overnight at $105{ }^{\circ} \mathrm{C}$, the $\mathrm{Ni} / \mathrm{Zr}-\mathrm{MOF}$ catalyst was devolatilized in a flowing nitrogen atmosphere from ambient temperature to $500{ }^{\circ} \mathrm{C}$ at $10{ }^{\circ} \mathrm{C} / \mathrm{min}$, and then held at $500{ }^{\circ} \mathrm{C}$ for $2 \mathrm{~h}$ before being stored and used further.

\section{Apparatus and procedure for biomass gasification}

The experiments were performed using a fixed bed reactor facility, as shown in Fig. 1. The biomass sample (1 $\mathrm{g}$ of wet sludge with a moisture content of $80 \%$ and $1 \mathrm{~g}$ of wheat straw) and quartz wool (Daiermeng Science and Technology, Wuxi, China) containing $1 \mathrm{~g}$ of Ni/Zr-MOF catalyst was placed in a porcelain boat. Before the experiment, high-purity nitrogen gas was introduced into the quartz tube for $30 \mathrm{~min}$ to exhaust the air in the quartz tube. The experiments were performed at $500{ }^{\circ} \mathrm{C}$. The holding time was set to $10 \mathrm{~min}$. Once 
the desired temperature was reached, the heating furnace was pushed to the position where the sample was located, and it was instantly gasified at the specified temperature. The noncondensable gases were collected with a gas collecting bag and the volume of produced gas was measured by a gas flow meter. The composition and content of the gas were measured by a gas analyzer.

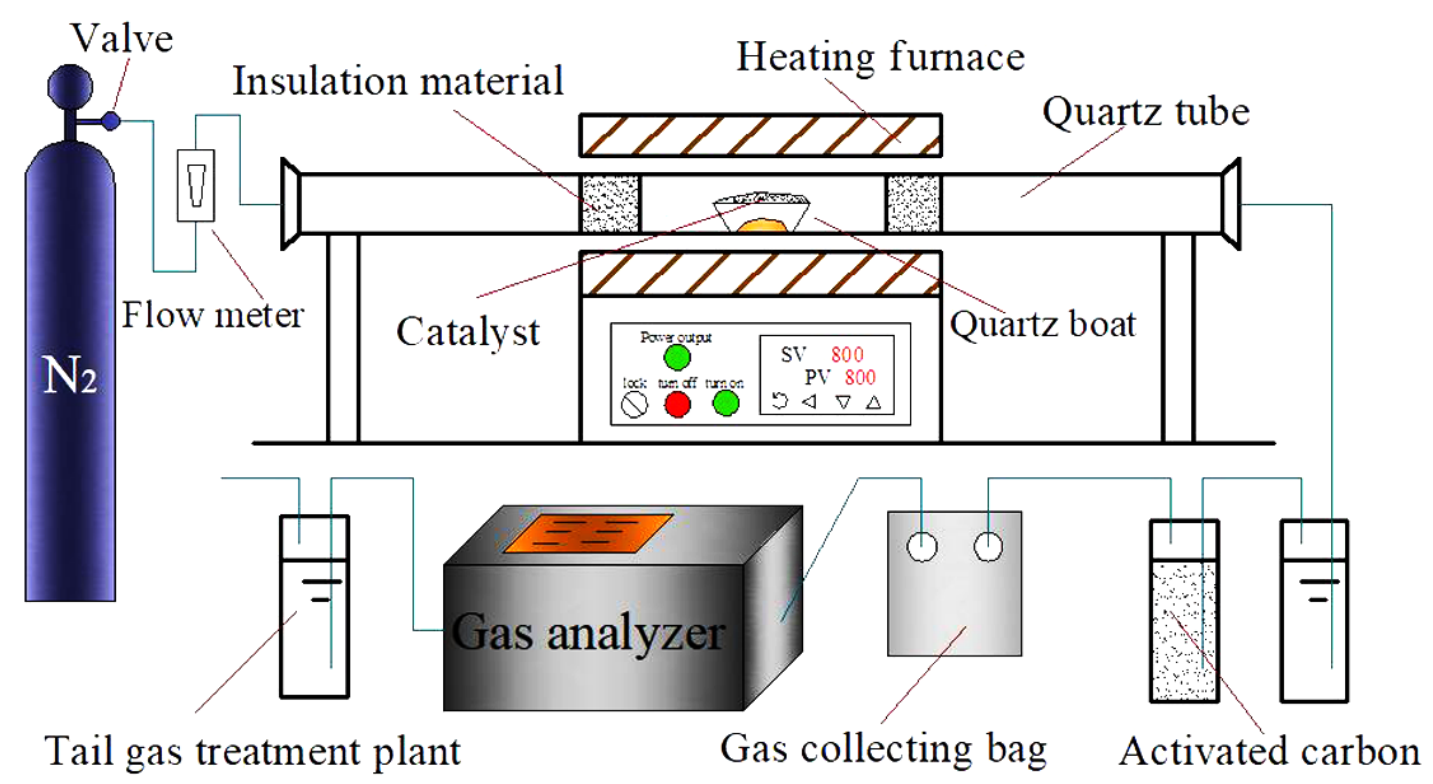

Fig. 1. Schematic diagram of the experimental system

\section{Methods}

Analysis

The ultimate analysis of the samples was conducted with a CHNS/O analyzer (FLASH2000; Thermo Fisher Scientific, Waltham, MA, USA). This analysis simultaneously gave the mass percentages of carbon, hydrogen, nitrogen, and sulfur in the samples, and the mass percent of oxygen was determined by the difference. The proximate analysis method of coal, according to GB/T 212 (2008), was used to obtain a proximate analysis of the sludge and wheat straw (i.e., moisture, volatile matter, fixed carbon, and ash content of the material). The material structure of the Ni/Zr-MOF catalyst was analyzed using an X-ray diffractometer (XRD-7000; Shimadzu Corp., Kyoto, Japan). The thermal stability of the support and catalyst were evaluated using a thermogravimetric analyzer (SDT Q600; TA Instruments, New Castle, DE, USA). Scanning electron microscopy (S9000; Tescan, Ltd., Brno, Czech) equipped with EDS was used to observe the surface morphology of the support and catalyst. The surface area and pore properties of the support and catalyst were determined by a surface area analyzer (ASAP 2020 HD88; Micromeritics Instrument Corp., Norcross, GA, USA). The gas composition analysis was conducted with an infrared gas analyzer (Gasboard-3100P; Hubei Cubic-Ruiyi Instrument Co., Wuhan, China). The lower heating value (LHV) of the product gas is defined by Lv et al. (2004) as follows,

$$
\operatorname{LHV}\left(\mathrm{kJ} / \mathrm{Nm}^{3}\right)=\left(27.5 \times \mathrm{H}_{2}+30 \times \mathrm{CO}+85.4 \times \mathrm{CH}_{4}+151.3 \times \mathrm{C}_{\mathrm{n}} \mathrm{H}_{\mathrm{m}}\right) \times 4.2
$$

where $\mathrm{H}_{2}, \mathrm{CO}, \mathrm{CH}_{4}$, and $\mathrm{C}_{\mathrm{n}} \mathrm{H}_{\mathrm{m}}$ are the gas concentrations (vol\%) of the product gas. 


\section{RESULTS AND DISCUSSION}

\section{Characterization of Catalysts}

TG analysis

Figure 2 shows the thermogravimetric analysis of the $\mathrm{Zr}-\mathrm{MOF}$ support and $\mathrm{Ni} / \mathrm{Zr}$ MOF catalyst under the $\mathrm{N}_{2}$ atmosphere. As shown by the dotted line in Fig. 2, with the increase of temperature, the TG profile of Ni/Zr-MOF catalyst was an almost horizontal straight line, which showed that the quality of the catalyst was almost unchanged. Consequently, the Ni/Zr-MOF catalyst had a high thermal stability. As shown by the solid line in Fig. 2, the Zr-MOF support presented mainly two stages in weight loss. The TG profile of $\mathrm{Zr}-\mathrm{MOF}$ support obtained in this experiment was consistent with the results reported by Ren et al. (2014). A continuous mass loss of Zr-MOF support before $350{ }^{\circ} \mathrm{C}$ likely corresponded to the removal of all organic material, including the evaporation of guest molecules from the pores such as the solvent DMF. Between temperatures of $350{ }^{\circ} \mathrm{C}$ and $500{ }^{\circ} \mathrm{C}$ the mass loss was almost linear, which indicated that the Zr-MOF support had high thermal stability under $500{ }^{\circ} \mathrm{C}$. The $\mathrm{Zr}$-MOF support maintained their structure up to $500{ }^{\circ} \mathrm{C}$ and after that a sudden weight loss was observed, which was attributed to decomposition of the $\mathrm{Zr}-\mathrm{MOF}$ to $\mathrm{ZrO}_{2}$.

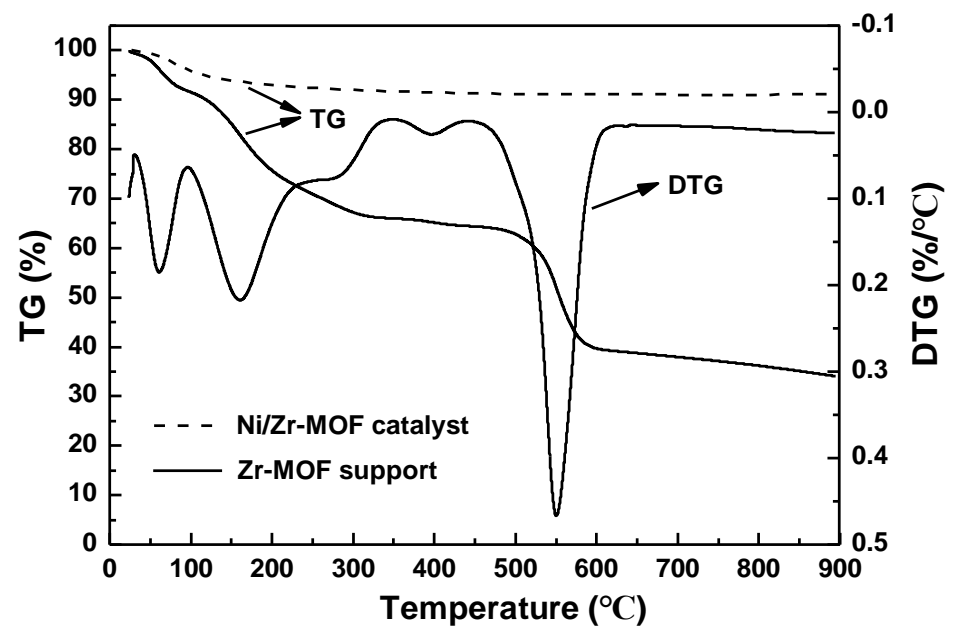

Fig. 2. TG analysis of $\mathrm{Zr}-\mathrm{MOF}$ support and $\mathrm{Ni} / \mathrm{Zr}-\mathrm{MOF}$ catalyst under the $\mathrm{N}_{2}$ atmosphere

\section{$X R D$ analysis}

Figure 3 shows the XRD patterns of three catalysts and Ni/Zr-MOF catalysts with different Ni loading. As shown in Fig. 3(a), in the Ni/Zr-MOF catalyst, the peaks at $2 \theta=$ $37.3^{\circ}, 43.3^{\circ}, 62.8^{\circ}, 75.4^{\circ}$, and $79.5^{\circ}$ were observed and identified as $\mathrm{NiO}$ (PDF\#89-5881). According to the Scherrer formula, the average size of the $\mathrm{NiO}$ grains in the $\mathrm{Ni} / \mathrm{Zr}-\mathrm{MOF}$ catalyst was approximately $10 \mathrm{~nm}$, which indicated that $\mathrm{NiO}$ had good dispersion on the $\mathrm{Zr}$-MOF support. After catalytic cracking, the active components of Ni/Zr-MOF catalyst had changed. The characteristic diffraction peaks of $\mathrm{Ni}$ (111), $\mathrm{Ni}$ (200), and $\mathrm{Ni}$ (220) at $2 \theta$ $=44.4^{\circ}, 51.6^{\circ}$, and $76.1^{\circ}$ (PDF\#01-1258), respectively, were observed in the used Ni/ZrMOF catalyst. The average size of the Ni grains was approximately $12 \mathrm{~nm}$, which indicated that the metal nickel might agglomerate after 10 instances of reuse. The conversion of $\mathrm{NiO}$ to $\mathrm{Ni}$ was attributed to carbothermal reduction and hydrogenation reduction. Hu et al. (2018) showed that $\mathrm{NiO}$ was transformed into $\mathrm{Ni}$, which contributed to the enhancement 
of tar conversion. In addition, the strong peaks at $2 \theta=30.1^{\circ}, 34.9^{\circ}, 50.2^{\circ}$, and $59.7^{\circ}$ were observed and identified as $\mathrm{ZrO}_{2}$ (PDF\#89-9069), which indicated that the $\mathrm{Zr}$-metal organic framework was decomposed into $\mathrm{ZrO}_{2}$, and the metal organic framework might collapse. The characteristic diffraction peaks of $\mathrm{NiO}$ at $2 \theta=37.2^{\circ}, 43.9^{\circ}, 62.9^{\circ}, 75.4^{\circ}$, and $79.5^{\circ}$ (PDF\#89-7131), respectively, were observed in the regenerated catalyst. What's more, the characteristic peak intensity of $\mathrm{NiO}$ in the regenerated catalyst was higher than that of the $\mathrm{Ni} / \mathrm{Zr}-\mathrm{MOF}$ catalyst. As shown in Fig. 3(b), the NiO characteristic peaks became stronger and narrower with the increase of Ni loading.
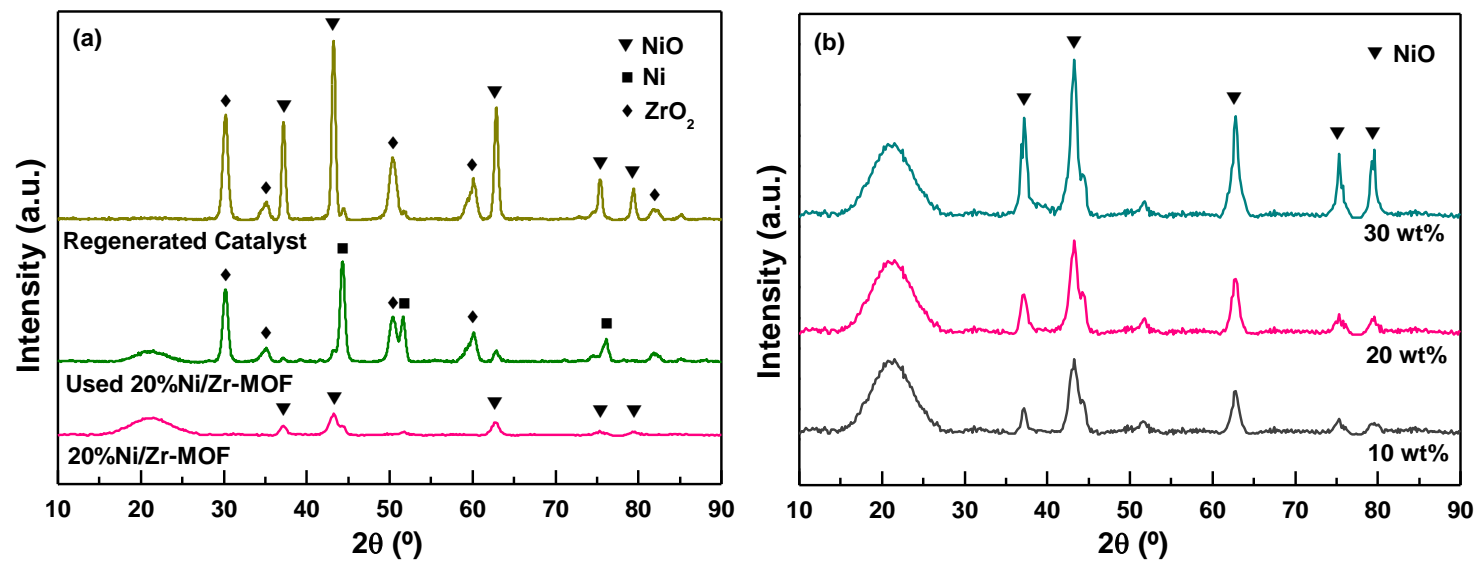

Fig. 3. XRD patterns of (a) three catalysts, and (b) Ni/Zr-MOF catalysts with different Ni loading

\section{SEM-EDS analysis}

Figure 4 shows the SEM images of the Zr-MOF support, Ni/Zr-MOF catalyst, and used Ni/Zr-MOF catalyst. Figure 4(a) shows that all of the Zr-MOF crystals took an octahedral shape with particle sizes of approximately $100 \mathrm{~nm}$. The analysis of Ni/Zr-MOF catalyst via SEM-EDS indicated that the octahedral morphologies of the Zr-MOF crystals were maintained, and nickel was uniformly dispersed on the surface of the Zr-MOF support, which provided more active sites for the Ni/Zr-MOF catalyst. Moreover, the pore structure of the Ni/Zr-MOF catalyst was still clear, which is conducive to the diffusion of tar in the catalyst. This is noticeable in the SEM image and was confirmed by the EDS analysis (Fig. 4(b)). According to EDS analysis, the metal nickel had been successfully loaded on the Zr-MOF support. However, it can be observed from Fig. 4(c) that most of the octahedron structure of the Ni/Zr-MOF catalyst collapsed after reuse. Additionally, only the $\mathrm{Zr}$-MOF crystal with the larger particle size retained the octahedron structure, and the agglomeration of nickel resulted in the increase of particle size.

\section{BET analysis}

The $\mathrm{N}_{2}$ adsorption and desorption isotherms of the $\mathrm{Zr}-\mathrm{MOF}$ support, Ni/Zr-MOF catalyst, and used Ni/Zr-MOF catalyst, are presented in Fig. 5. The pore sizes of the three samples were mainly distributed between $0 \mathrm{~nm}$ to $50 \mathrm{~nm}$. Additionally, all the isotherms were of the type 4 pattern according to the IUPAC classification, which corresponded to the mesoporous structure of the three samples. The mesoporous structure of the Ni/ZrMOF catalyst had adsorption capacity for tar, which could promote the contact between tar and active components to produce more hydrogen-rich syngas from cracking tar. 

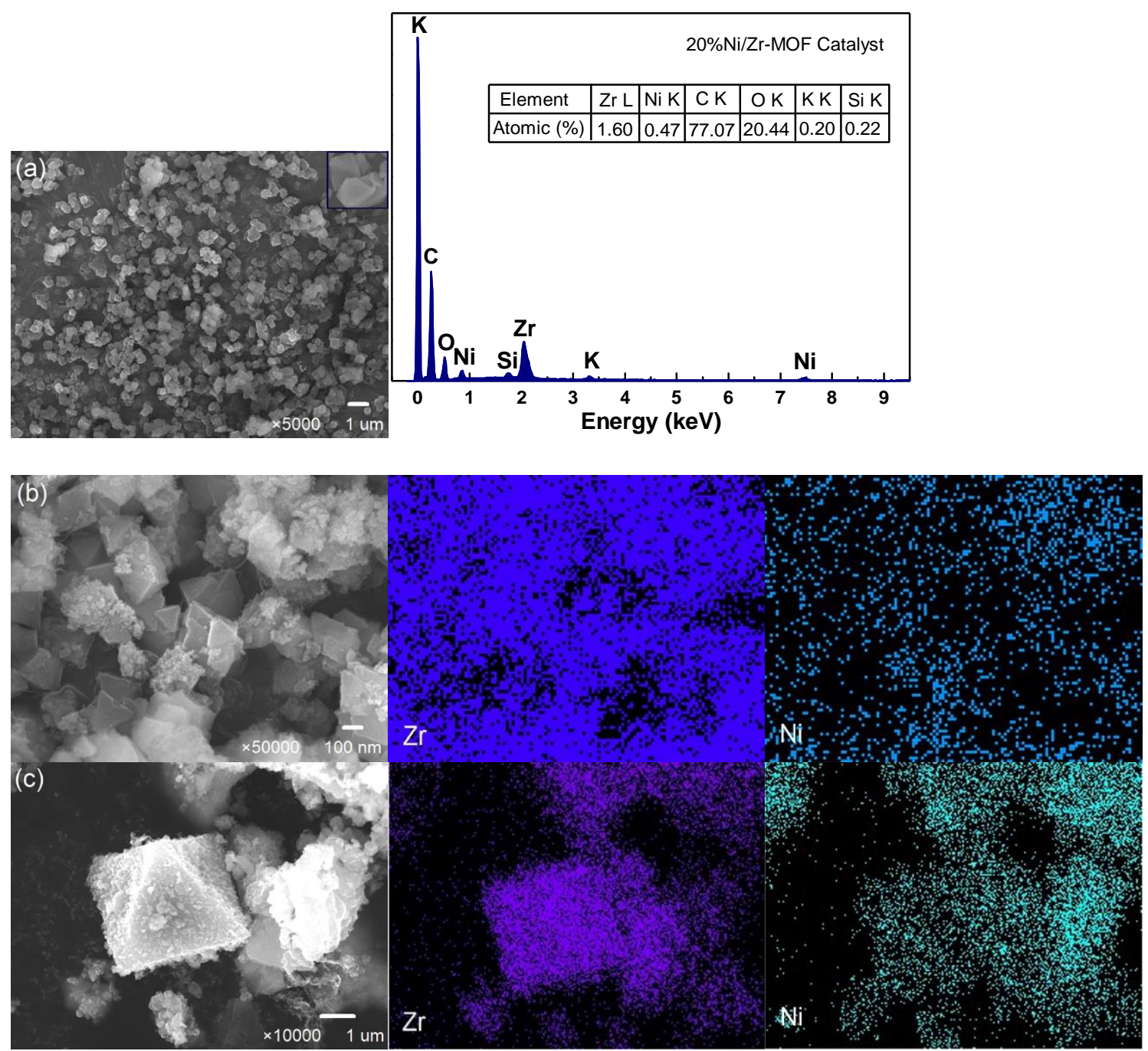

Fig. 4. SEM image of (a) Zr-MOF support, SEM-EDS images of (b) Ni/Zr-MOF catalyst, and (c) used $\mathrm{Ni} / \mathrm{Zr}$-MOF catalyst

The textural parameters of $\mathrm{Zr}-\mathrm{MOF}$ support, Ni/Zr-MOF catalyst, and used Ni/ZrMOF catalyst, including BET surface area, total pore volume, and average pore diameter, are listed in Table 3. It was found that the BET surface area of Zr-MOF support was 806 $\mathrm{m}^{2} / \mathrm{g}$, the pore volume was $0.47 \mathrm{~cm}^{3} / \mathrm{g}$, and the pore diameter was $20.14 \mathrm{~nm}$. A large number of studies have shown that supports with larger BET surface areas can promote the dispersion of metal elements on the surface of a catalyst, and a larger pore diameter is beneficial to the diffusion of reactants and products in the channel of catalyst, so as to improve the catalytic activity of the catalyst (Shen et al. 2011). Furthermore, it was found that the BET surface area and pore volume of the Ni/Zr-MOF catalyst decreased after reuse. Carbon deposition of the Ni/Zr-MOF catalyst blocked some micropores, which resulted in a decrease in the BET surface area. Compared with the fresh Ni/Zr-MOF catalyst, the used $\mathrm{Ni} / \mathrm{Zr}-\mathrm{MOF}$ catalyst had a larger pore diameter due to the destruction of the $\mathrm{Zr}-\mathrm{MOF}$ support structure after reuse. 

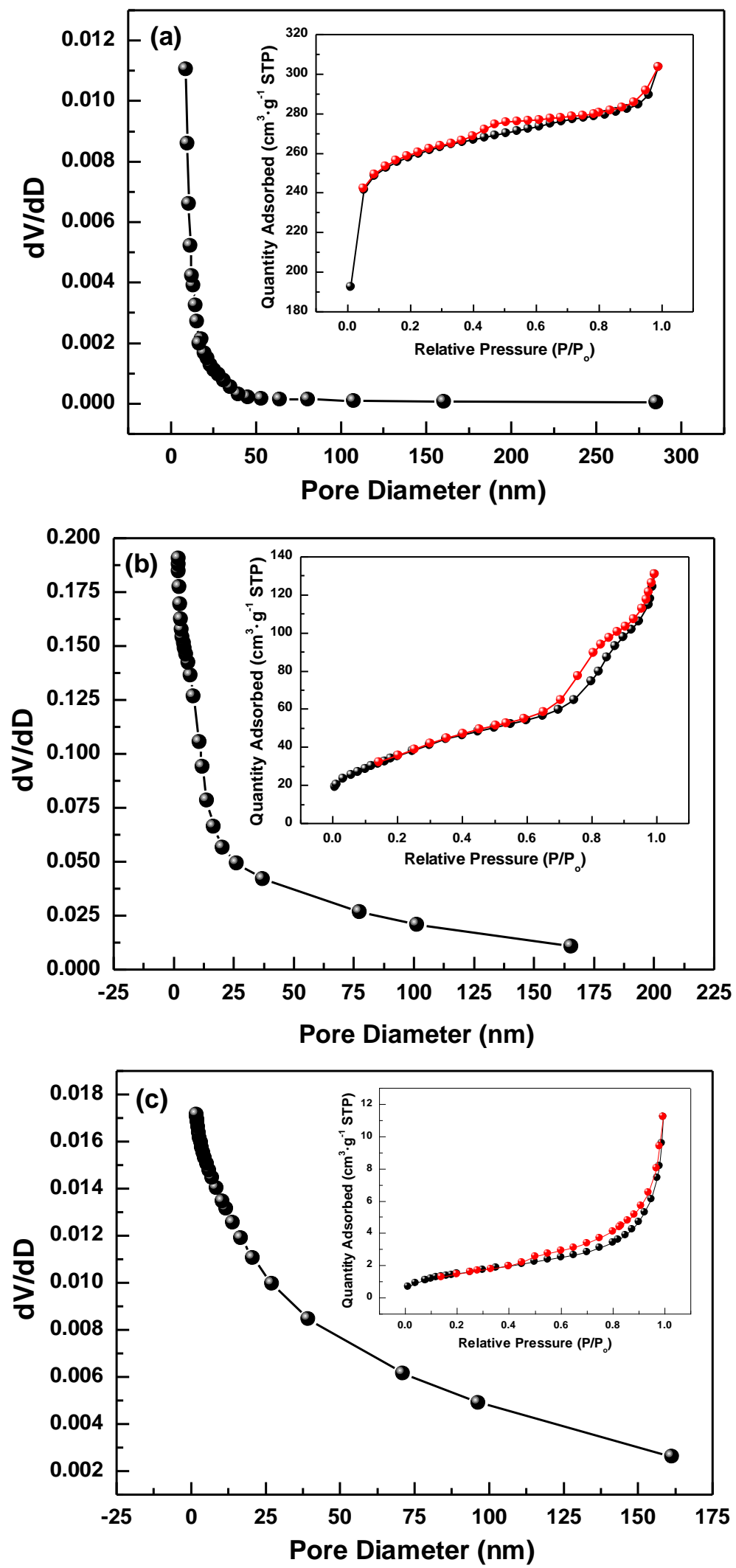

Fig. 5. $\mathrm{N}_{2}$ adsorption-desorption isotherm plots and pore distribution of $\mathrm{Zr}$-MOF support (a), $\mathrm{Ni} / \mathrm{Zr}$ MOF catalyst (b), and used Ni/Zr-MOF catalyst (c) 
Table 2. Textural Parameters of Zr-MOF Support, Ni/Zr-MOF Catalyst, and Used $\mathrm{Ni} / \mathrm{Zr}-\mathrm{MOF}$ Catalyst

\begin{tabular}{|c|c|c|c|}
\hline Sample & $\begin{array}{c}\text { BET Surface } \\
\text { Area }\left(\mathrm{m}^{2} / \mathrm{g}\right)\end{array}$ & $\begin{array}{c}\text { Total Pore } \\
\text { Volume }\left(\mathrm{cm}^{3} / \mathrm{g}\right)\end{array}$ & $\begin{array}{c}\text { Average Pore } \\
\text { Diameter }(\mathrm{nm})\end{array}$ \\
\hline Zr-MOF & 805.9 & 0.47 & 20.14 \\
\hline Ni/Zr-MOF Catalyst & 132.7 & 0.19 & 7.39 \\
\hline Used Ni/Zr-MOF Catalyst & 5.64 & 0.02 & 11.96 \\
\hline
\end{tabular}

\section{Application and Analysis of Ni/Zr-MOF Catalyst in Biomass Gasification}

The important reactions that took place during catalytic gasification of wet sludge and wheat straw were summarized as follows (Hu et al. 2015; Yang et al. 2018):

Drying process: Wet sample $\rightarrow$ steam + dry sample

Pyrolysis: Dry sample $\rightarrow$ gas + tar + char

Secondary cracking: Tar $\rightarrow \mathrm{H}_{2}+\mathrm{CO}+\mathrm{CO}_{2}+\mathrm{CH}_{4}+\mathrm{H}_{2} \mathrm{O}+\mathrm{C}_{\mathrm{n}} \mathrm{H}_{m}$

Steam gasification reaction: $\mathrm{C}_{\mathrm{n}} \mathrm{H}_{\mathrm{m}}+\mathrm{nH}_{2} \mathrm{O}+\mathrm{Q} \rightarrow \mathrm{nCO}+[\mathrm{n}+(\mathrm{m} / 2)] \mathrm{H}_{2}$

Methane reforming reaction: $\mathrm{CH}_{4}+\mathrm{H}_{2} \mathrm{O} \rightarrow \mathrm{CO}+3 \mathrm{H}_{2}+206 \mathrm{~kJ} / \mathrm{mol}$

Water gas shift reaction: $\mathrm{CO}+\mathrm{H}_{2} \mathrm{O} \rightarrow \mathrm{CO}_{2}+\mathrm{H}_{2}-41 \mathrm{~kJ} / \mathrm{mol}$

Char steam gasification reaction: $\mathrm{C}+\mathrm{H}_{2} \mathrm{O} \rightarrow \mathrm{CO}+\mathrm{H}_{2}+131 \mathrm{~kJ} / \mathrm{mol}$

Boudouard reaction: $\mathrm{C}+\mathrm{CO}_{2} \rightarrow 2 \mathrm{CO}+172 \mathrm{~kJ} / \mathrm{mol}$

Figure 6 shows the processes of biomass catalytic gasification. First, the drying process of the wet sample took place at a high temperature, which formed in-situ steam around the sample (Eq. 2). Meanwhile, the dry sample was rapidly pyrolyzed to gas, tar, and char (Eq. 3), followed by secondary cracking of the tar to form gas and small molecule organic matter (Eq. 4), steam gasification reaction, methane reforming reaction, water gas shift reaction, char steam gasification reaction, and the Boudouard reaction (Eqs. 5 through 9).

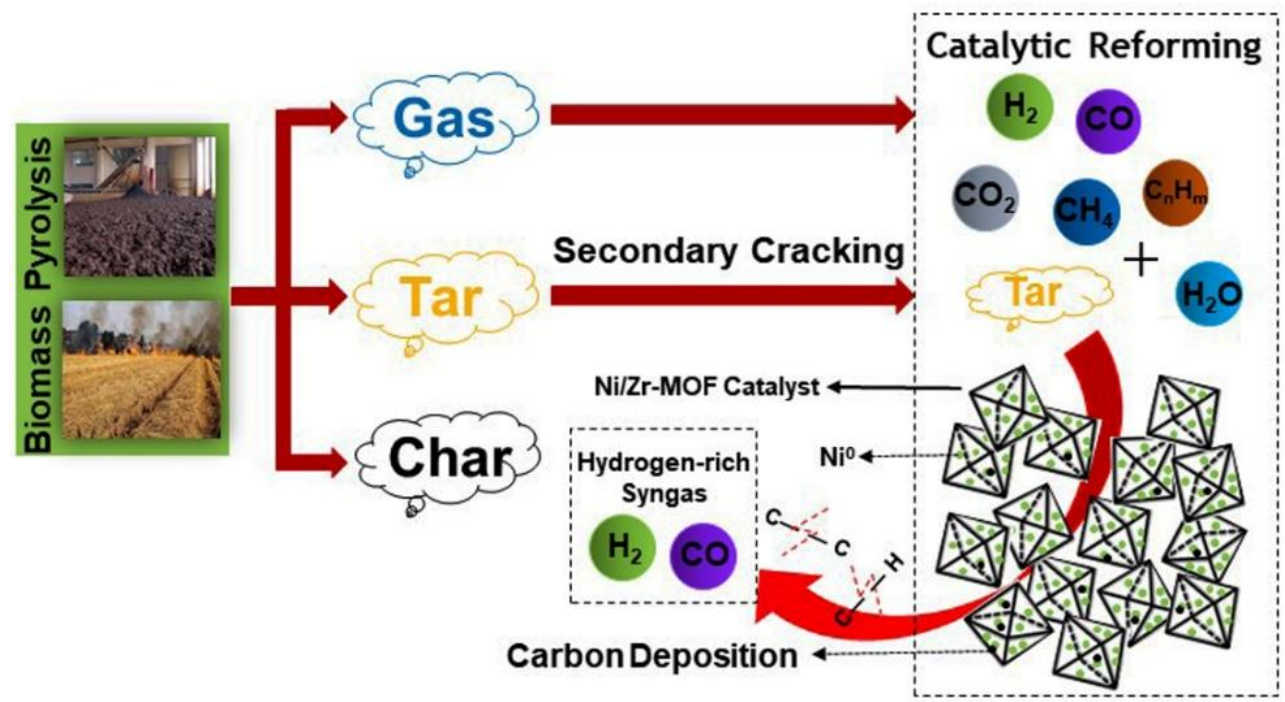

Fig. 6. Mechanism of catalytic gasification of biomass using Ni/Zr-MOF catalyst 
The primary gas was produced from the thermal scission of chemical bonds in the individual constituents of biomass, when catalytic reforming reactions cleaved the $\mathrm{C}-\mathrm{C}$ and $\mathrm{C}-\mathrm{H}$ bonds of the carbohydrate backbone to produce $\mathrm{CO}$ and $\mathrm{H}_{2}$ (Kunkes et al. 2008). Due to the presence of in-situ steam, the char steam gasification reaction not only could refresh the active surface area of the catalyst by reducing the carbon deposit of the catalyst, but it also increased the $\mathrm{CO}$ and $\mathrm{H}_{2}$ content in the gas.

\section{Influence of catalyst on gas composition}

The Ni/Zr-MOF catalyst was used for tar cracking and improving gas quality in the catalytic in-situ steam gasification of wet sludge and straw, compared with the case without catalyst. The influence of the Ni/Zr-MOF catalyst on gas composition and characterization under $500{ }^{\circ} \mathrm{C}$ are shown in Fig. 7 and Table 3. The main components in the gas were $\mathrm{H}_{2}$, $\mathrm{CO}, \mathrm{CH}_{4}$, and $\mathrm{CO}_{2}$, which accounted for more than $98 \%$ of the gas, in addition to a small amount of $\mathrm{C}_{\mathrm{n}} \mathrm{H}_{\mathrm{m}}$. From the view of overall production, with the addition of the Ni/Zr-MOF catalyst, the dry gas yield showed a noticeable growth trend, from 0.45 to $0.56 \mathrm{~N} \cdot \mathrm{m}^{3} / \mathrm{kg}$. Additionally, $\mathrm{CO}$ was the leading component in hydrogen-rich syngas without the addition of catalyst, accounting for $55.07 \mathrm{vol} \%$. With the Ni/Zr-MOF catalyst, the content of $\mathrm{H}_{2}$ remarkably increased from 1.94 vol\% to 47.49 vol\%, and the $\mathrm{H}_{2}$ yield increased from 0.39 $\mathrm{mol} / \mathrm{kg}$ to $11.87 \mathrm{~mol} / \mathrm{kg}$, while the CO content decreased to $13.15 \mathrm{vol} \%$. The LHV of gas decreased from $15.51 \mathrm{MJ} / \mathrm{N} \cdot \mathrm{m}^{3}$ to $12.01 \mathrm{MJ} / \mathrm{N} \cdot \mathrm{m}^{3}$, because the calorific values of $\mathrm{CH}_{4}$ and $\mathrm{C}_{\mathrm{n}} \mathrm{H}_{\mathrm{m}}$ were higher than that of $\mathrm{H}_{2}$ or $\mathrm{CO}$. Consequently, the hydrogen-rich syngas yield was dramatically increased under the Ni/Zr-MOF catalyst due to various effects.

First of all, according to the SEM-EDS and BET analyses, the Zr-MOF support had an octahedral structure with a larger specific surface area of $806 \mathrm{~m}^{2} / \mathrm{g}$, which allowed the metal nickel to be uniformly dispersed on the surface of the support, thereby improving the dispersion of metal, increasing the active sites of the catalyst, and improving the activity of the catalyst. Chan and Tanksale (2014) showed that the support material played an important role in defining the activity and service life of the catalyst, and catalysts with high surface area supports generally exhibited higher catalytic activity. Zhao et al. (2009) prepared $\mathrm{Ni} / \mathrm{Al}_{2} \mathrm{O}_{3}$ and $\mathrm{Ni} / \mathrm{MCM}-41$ catalysts, supported on $\mathrm{Al}_{2} \mathrm{O}_{3}$ and $\mathrm{MCM}-41$, respectively, which were tested for their performance on the pyrolytic decomposition of cellulose. It was found that the specific surface areas of $\mathrm{Al}_{2} \mathrm{O}_{3}$ and MCM-41 were $155 \mathrm{~m}^{2} / \mathrm{g}$ and $979 \mathrm{~m}^{2} / \mathrm{g}$, respectively. MCM-41 had a highly ordered hexagonal porous structure. The $\mathrm{NiO}$ particles were uniformly dispersed on the surface of the MCM-41 support. Furthermore, the shape of the $\mathrm{NiO}$ particles was regular, and the pore structure of MCM41 was the same as that of MCM-41. Compared with the $\mathrm{Ni} / \mathrm{Al}_{2} \mathrm{O}_{3}$ catalyst, the Ni/MCM41 catalyst could remarkably improve the yield of $\mathrm{H}_{2}$ and total gaseous products and had a higher catalytic activity for the cracking and reforming of tar and light organic compounds.

Secondly, according to the BET analysis, the pore volume and average pore diameter of the Ni/Zr-MOF catalyst were $0.19 \mathrm{~cm}^{3} / \mathrm{g}$ and $7.39 \mathrm{~nm}$, respectively. Therefore, the Ni/Zr-MOF catalyst had a mesoporous structure and good adsorption performance for tar, which promoted the catalytic cracking of tar to produce more hydrogen. In addition, the larger pore diameter was beneficial to the diffusion of reactants and products in the channel of the catalyst. Grams et al. (2016) prepared Ni/SBA-15, Ni/SBA-16, Ni/KIT-6, and $\mathrm{Ni} / \mathrm{MCM}-41$ catalysts with different mesoporous silica materials as supports, which were used in the thermo-chemical conversion of cellulose to produce hydrogen-rich syngas. The results showed that Ni/SBA-15 and Ni/KIT-6 catalysts had larger pore volumes and pore diameters. The larger pore volumes and pore diameters facilitated 
penetration of the catalyst structure by heavier reaction intermediates and full contact with the active site of the catalyst, which allowed for more efficient hydrogen formation. As shown in Table 3, the $\mathrm{H}_{2}$ yield was remarkably increased from $0.39 \mathrm{~mol} / \mathrm{kg}$ to $11.87 \mathrm{~mol} / \mathrm{kg}$ using the Ni/Zr-MOF catalyst. In conclusion, the newly developed Ni/Zr-MOF catalyst had high catalytic performance in the production of hydrogen-rich syngas.

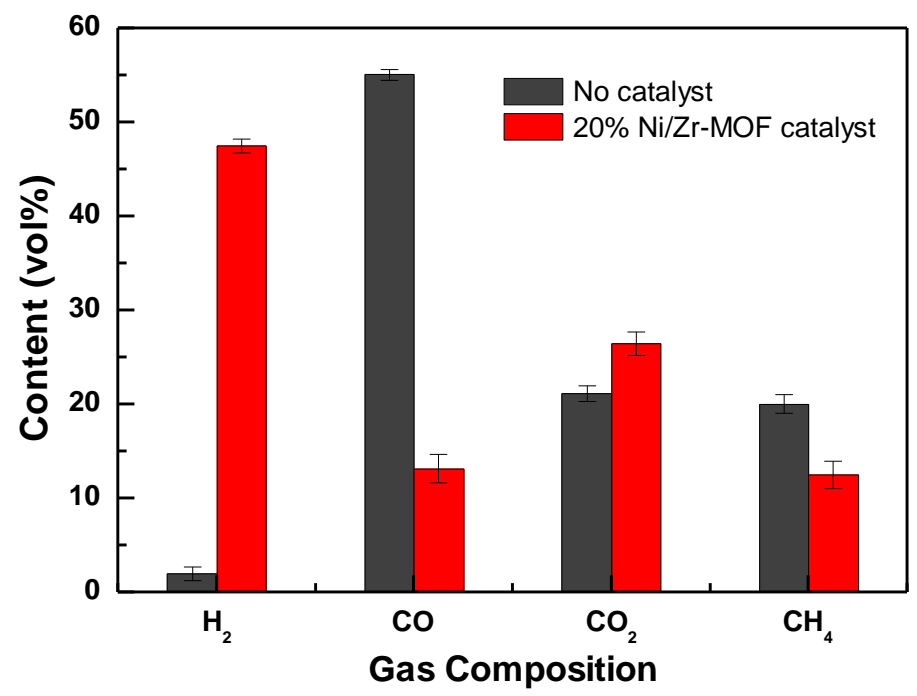

Fig. 7. Influence of catalyst on gas composition

Table 3. Influence of Catalyst on Gas Composition and Gas Characterization

\begin{tabular}{|c|c|c|}
\hline Catalyst & No Catalyst & $20 \%$ Ni/Zr-MOF Catalyst \\
\hline Gasification Temperature $\left({ }^{\circ} \mathrm{C}\right)$ & 500 & 500 \\
\hline Catalytic Temperature $\left({ }^{\circ} \mathrm{C}\right)$ & 500 & 500 \\
\hline $\mathrm{H}_{2}$ Content $($ vol\%) & 1.94 & 47.49 \\
\hline $\mathrm{CO}$ Content $(\mathrm{vol} \%)_{\mathrm{CH}_{4} \text { Content }(\mathrm{vol} \%)}^{55.07}$ & 13.15 \\
\hline $\mathrm{CO}_{2}$ Content $(\mathrm{vol} \%)$ & 20.03 & 12.50 \\
\hline $\mathrm{C}_{n} \mathrm{H}_{\mathrm{m}}$ Content $(\mathrm{vol} \%)$ & 21.12 & 26.46 \\
\hline Dry Gas Yield $\left(\mathrm{N} \mathrm{m}^{3} / \mathrm{kg}\right)$ & 1.83 & 0.40 \\
\hline $\mathrm{H}_{2}$ Yield $\left(\mathrm{mol}^{3} / \mathrm{kg}\right)$ & 0.45 & 0.56 \\
\hline $\mathrm{LHV}\left(\mathrm{MJ} / \mathrm{N} \mathrm{m}^{3}\right)$ & 0.39 & 11.87 \\
\hline & 15.51 & 12.01 \\
\hline
\end{tabular}

Influence of Ni loading on syngas conetnt

The influence of Ni loading on syngas content was studied with the Ni/Zr-MOF catalyst under $500{ }^{\circ} \mathrm{C}$. As shown in Fig. 8, when the nickel loading was $0 \%$, the content of $\mathrm{H}_{2}$ and $\mathrm{CO}$ was similar to the case without catalyst, which showed that the $\mathrm{Zr}-\mathrm{MOF}$ support itself had no catalytic activity. With the increased loading of $\mathrm{Ni}$ from $5 \%$ to $20 \%$, the $\mathrm{H}_{2}$ content remarkably increased from $30.57 \%$ to $47.49 \%$, which indicated that Ni played a vital role in the promotion of $\mathrm{H}_{2}$ generation. However, when the Ni loading was further increased from $20 \%$ to $30 \%$, the $\mathrm{H}_{2}$ content showed a slight decrease, from $47.49 \%$ to $41.67 \%$. At the same time, it can be found that with the increase of Ni loading, the CO content presented a gradually decreasing trend.

With the increase of Ni loading, the number of active sites in Ni/Zr-MOF catalyst gradually increased, so the catalytic efficiency of the catalyst gradually increased. However, when the Ni loading was too high, a large amount of Ni entered into the pores 
of Zr-MOF support, thus blocking the pore structure of catalyst. What's more, Quan et al. (2017) showed that high loading of NiO could decrease the dispersion of metal and also increase the aggregation of active sites. Consequently, the active sites which can contact with tar macromolecules will be reduced, thus resulting in the decrease of catalytic activity in Ni/Zr-MOF catalyst. It can be observed from Fig. 3(b) that the NiO characteristic peaks became stronger and narrower with the increase of $\mathrm{Ni}$ loading, indicating that the crystal size of $\mathrm{NiO}$ particles increased. According to the Scherrer formula, the average size of $\mathrm{NiO}$ grains in the Ni/Zr-MOF catalyst was $9 \mathrm{~nm}, 10 \mathrm{~nm}$, and $12 \mathrm{~nm}$, respectively. Therefore, 20 wt $\%$ was the optimal Ni loading for Ni/Zr-MOF catalyst.

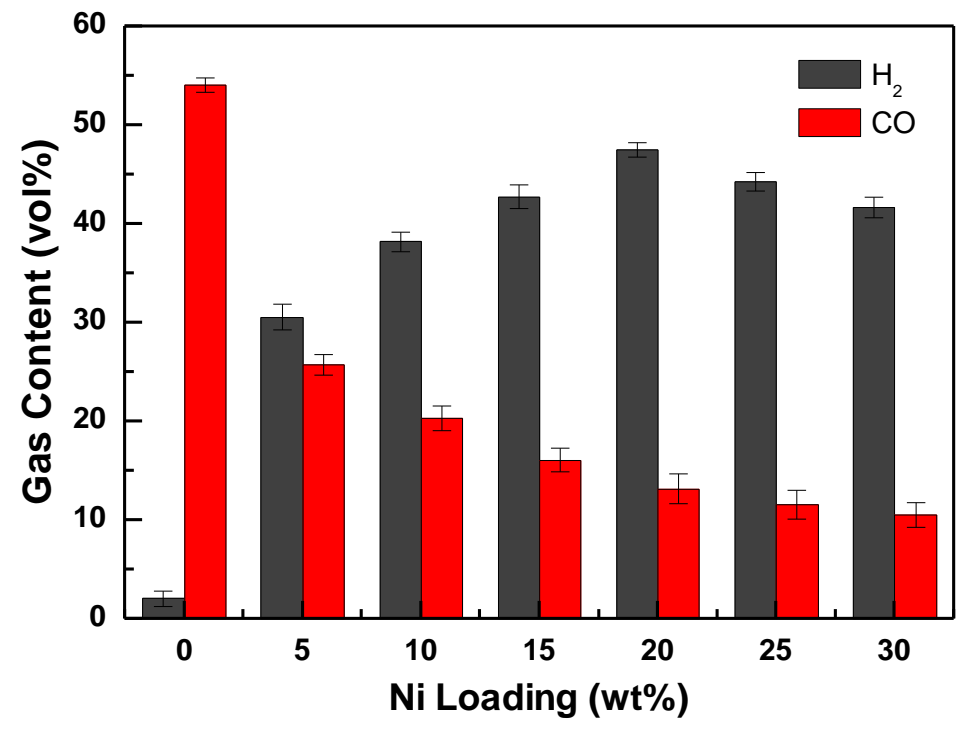

Fig. 8. Influence of Ni loading on syngas content

\section{Catalyst cyclability}

The superior catalytic performance of $\mathrm{Ni} / \mathrm{Zr}-\mathrm{MOF}$ has been shown from the above catalyst characterization and experimental results. These results showed that it would be meaningful to further explore its cycling stability. The testing results of the 10-cycling that used Ni/Zr-MOF catalyst are shown in Fig. 9. With the increase of cycle test times, the catalytic performance of the $\mathrm{Ni} / \mathrm{Zr}-\mathrm{MOF}$ catalyst decreased gradually, and the $\mathrm{H}_{2}$ content decreased from $48.22 \mathrm{vol} \%$ to $42.74 \mathrm{vol} \%$. The $\mathrm{H}_{2}$ yields were, respectively, $12.05 \mathrm{~mol} / \mathrm{kg}$ and $10.11 \mathrm{~mol} / \mathrm{kg}$ after the Ni/Zr-MOF catalyst was used one and ten times, and the corresponding $\mathrm{H}_{2}$ yield was decreased $16.1 \%$.

The 10-cycling that used Ni/Zr-MOF catalyst was characterized by XRD, SEMEDS, and BET. By comparing the fresh catalyst shown in Fig. 4(b) with the recycle used shown in Fig. 4(c), most of the octahedral morphology of the Ni/Zr-MOF catalyst had collapsed, and the metal nickel had agglomerated. The XRD patterns showed that the active component of the $\mathrm{Ni} / \mathrm{Zr}-\mathrm{MOF}$ catalyst was transformed from $\mathrm{NiO}$ to $\mathrm{Ni}$ after recycling, which might have consumed a small amount of hydrogen. In addition, the nickel particle size increased from $10 \mathrm{~nm}$ to $12 \mathrm{~nm}$, which also confirmed the agglomeration of nickel. This would reduce the active sites of the Ni/Zr-MOF catalyst, thereby reducing the catalytic activity of the catalyst. According to the BET analysis, the pore volume of Ni/Zr-MOF catalyst decreased from $0.19 \mathrm{~cm}^{3} / \mathrm{g}$ to $0.02 \mathrm{~cm}^{3} / \mathrm{g}$ due to the carbon deposition blocking the pore channel of the catalyst, which was not conducive to the diffusion of tar in the catalyst. 


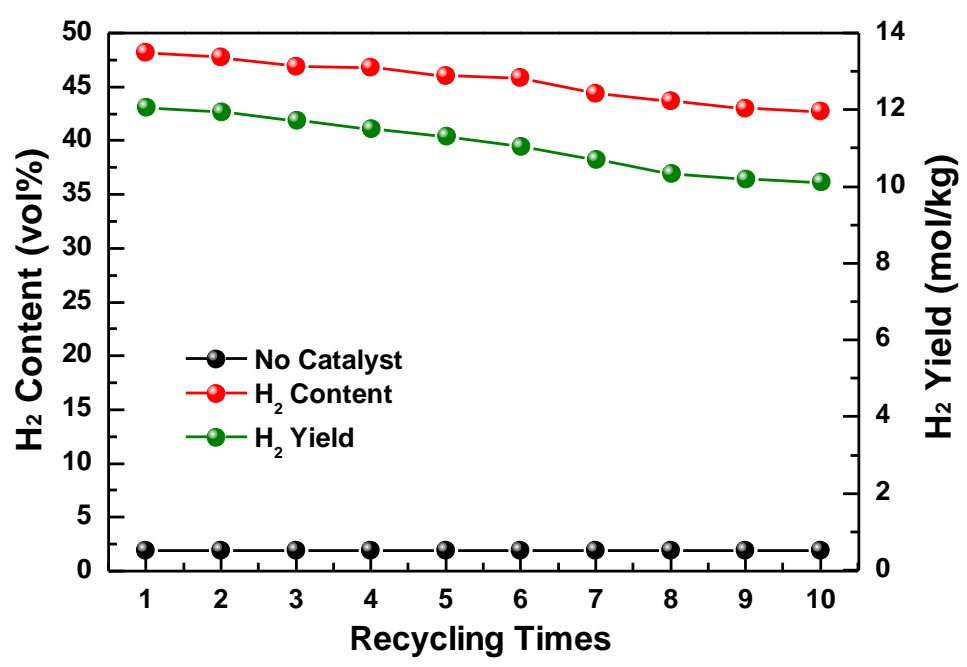

Fig. 9. The $\mathrm{H}_{2}$ content and $\mathrm{H}_{2}$ yield of cycling test with $20 \% \mathrm{Ni} / \mathrm{Zr}-\mathrm{MOF}$ catalyst under $500{ }^{\circ} \mathrm{C}$

\section{Regeneration of the used catalyst}

The catalyst will be deactivated after repeated use. Therefore, it is meaningful to study the regeneration performance of catalyst for reuse. The regenerated catalyst was prepared by calcining the used catalyst from ambient temperature to $600{ }^{\circ} \mathrm{C}$ with a rate of $10{ }^{\circ} \mathrm{C} / \mathrm{min}$ in an air atmosphere and maintained at $600{ }^{\circ} \mathrm{C}$ for $2 \mathrm{~h}$. Compared with the fresh catalyst, the catalytic performance of regenerated catalyst was evaluated and shown in Fig. 10. It can be observed that the catalytic performance of regenerated catalyst for hydrogenrich syngas production increased slightly. Among them, the $\mathrm{H}_{2}$ content increased from $47.49 \%$ to $51.17 \%$, and the CO content decreased from $13.15 \%$ to $12.72 \%$. According to Fig. 3(a), the characteristic peak intensity of $\mathrm{NiO}$ in the regenerated catalyst was higher than that of the fresh $\mathrm{Ni} / \mathrm{Zr}-\mathrm{MOF}$ catalyst, which meant that $\mathrm{NiO}$ particles in the regenerated catalyst had better crystallinity. Therefore, the regenerated catalyst had better catalytic activity.

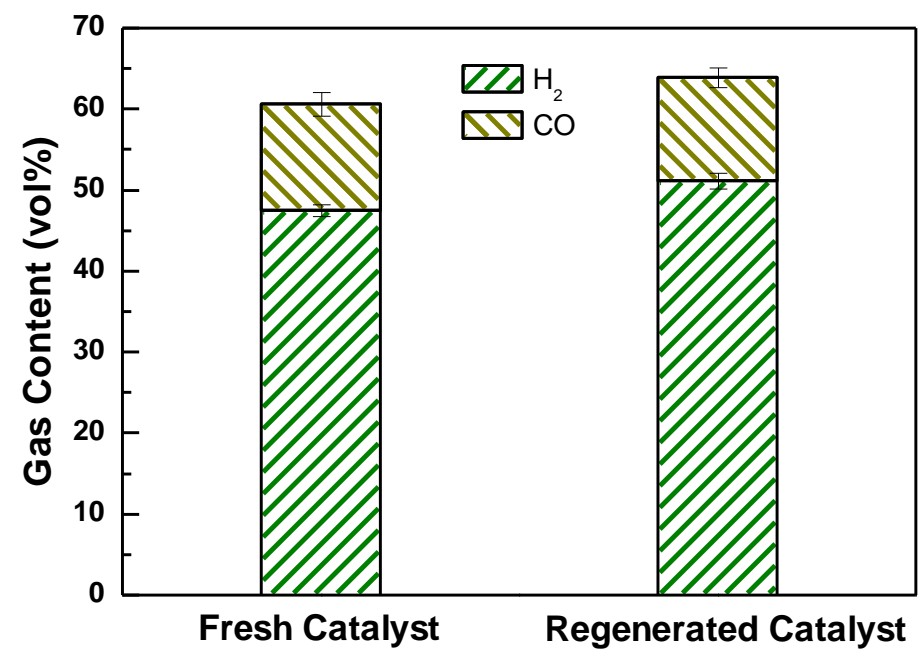

Fig. 10. Comparison of catalytic performance between fresh catalyst and regenerated catalyst 


\section{CONCLUSIONS}

1. All of the Zr-MOF crystals took an octahedral shape with particle size of approximately $100 \mathrm{~nm}$, and the Zr-MOF support had highly ordered mesoporous structure.

2. The Ni/Zr-MOF crystal was regular in shape, and most of them maintained the octahedral morphology. The metal nickel was uniformly dispersed on the surface of the Zr-MOF support.

3. After 10 tests, the sintering of catalyst resulted in the increase of nickel particle size from 10 to $12 \mathrm{~nm}$. Due to the collapse of the catalyst structure and carbon deposition, the surface area and pore volume decreased from 132.7 to $5.64 \mathrm{~m}^{2} / \mathrm{g}$ and 0.19 to 0.02 $\mathrm{cm} 3 / \mathrm{g}$, respectively.

4. The Ni/Zr-MOF catalyst showed high catalytic activity and thermal stability. With the $\mathrm{Ni} / \mathrm{Zr}-\mathrm{MOF}$ catalyst, the content of $\mathrm{H}_{2}$ remarkably increased from 1.94 vol\% to 47.49 vol\%, and the $\mathrm{H}_{2}$ yield increased from $0.39 \mathrm{~mol} / \mathrm{kg}$ to $11.87 \mathrm{~mol} / \mathrm{kg}$.

5. The increase of Ni loading could promote the generation of hydrogen-rich syngas, but excessive nickel would agglomerate. $20 \mathrm{wt} \%$ was the optimal Ni loading for $\mathrm{Ni} / \mathrm{Zr}$ MOF catalyst.

6. After 10 tests, the $\mathrm{Ni} / \mathrm{Zr}-\mathrm{MOF}$ catalyst exhibited excellent cycle stability, and the $\mathrm{H}_{2}$ content decreased from $48.22 \mathrm{vol} \%$ to $42.74 \mathrm{vol} \%$. In addition, the $\mathrm{H}_{2}$ yield decreased from 12.05 to $10.11 \mathrm{~mol} / \mathrm{kg}$, representing a decrease of only $16.1 \%$.

\section{ACKNOWLEDGMENTS}

The authors are grateful for the support of the Technology Innovation Major Project of Hubei Province (No. 2017ABA155), the Central Committee Guide Local Science and Technology Development Special Project of Hubei Province (No. 2018ZYYD062), and the Hubei Provincial Natural Science Foundation of China (No. 2018CFB280).

\section{REFERENCES CITED}

Chan, F. L., and Tanksale, A. (2014). "Review of recent developments in Ni-based catalysts for biomass gasification," Renew. Sust. Energ. Rev. 38, 428-438. DOI: 10.1016/j.rser.2014.06.011

GB/T 212 (2008). "Proximate analysis of coal," Standardization Administration of China, Beijing, China.

Grams, J., Potrzebowska, N., Goscianska, J., Michalkiewicz, B., and Ruppert, A. M. (2016). "Mesoporous silicas as supports for Ni catalyst used in cellulose conversion to hydrogen rich gas," Int. J. Hydrogen Energ. 41(20), 8656-8667. DOI:

10.1016/j.ijhydene.2015.12.146

Guan, G., Kaewpanha, M., Hao, X., and Abudula, A. (2016). "Catalytic steam reforming of biomass tar: Prospects and challenges," Renew. Sust. Energ. Rev. 58, 450-461.

DOI: $10.1016 /$ j.rser.2015.12.316 
Han, J., and Kim, H. (2008). "The reduction and control technology of tar during biomass gasification/pyrolysis: An overview," Renew. Sust. Energ. Rev. 12(2), 397-416. DOI: 10.1016/j.rser.2006.07.015

Hu, M., Guo, D., Ma, C., Hu, Z., Zhang, B., Xiao, B., Luo, S., and Wang, J. (2015). "Hydrogen-rich gas production by the gasification of wet MSW (municipal solid waste) coupled with carbon dioxide capture," Energy 90(Part 1), 857-863. DOI: 10.1016/j.energy.2015.07.122

Hu, M., Laghari, M., Cui, B., Xiao, B., Zhang, B., and Guo, D. (2018). "Catalytic cracking of biomass tar over char supported nickel catalyst," Energy 145, 228-237. DOI: 10.1016/j.energy.2017.12.096

Ismail, T. M., and El-Salam, M. A. (2017). "Parametric studies on biomass gasification process on updraft gasifier high temperature air gasification," Appl. Therm. Eng. 112, 1460-1473. DOI: 10.1016/j.applthermaleng.2016.10.026

Kunkes, E. L., Simonetti, D. A., West, R. M., Juan Carlos, S.-R., Gärtner, C. A., and Dumesic, J. A. (2008). "Catalytic conversion of biomass to monofunctional hydrocarbons and targeted liquid-fuel classes," Science 322(5900), 417-421. DOI: 10.1126/science. 1159210

Quan, C., Gao, N. B., and Wu, C. F. (2017). "Utilization of NiO/porous ceramic monolithic catalyst for upgrading biomass fuel gas," J. Energy Inst. 91(3), 1-8. DOI: 10.1016/j.joei.2017.02.008

Ren, J., Langmi, H. W., North, B. C., Mathe, M., and Bessarabov, D. (2014). "Modulated synthesis of zirconium-metal organic framework (Zr-MOF) for hydrogen storage applications," Int. J. Hydrogen Energ. 39(2), 890-895. DOI: 10.1016/j.ijhydene.2013.10.087

Saxena, R. C., Adhikari, D. K., and Goyal, H. B. (2009). "Biomass-based energy fuel through biochemical routes: A review," Renew. Sust. Energ. Rev. 131, 167-178. DOI: 10.1016/j.rser.2007.07.011

Shen, W., Momoi, H., Komatsubara, K., Saito, T., Yoshida, A., and Naito, S. (2011). "Marked role of mesopores for the prevention of sintering and carbon deposition in dry reforming of methane over ordered mesoporous Ni-Mg-Al oxides," Catal. Today 171(1), 150-155. DOI: 10.1016/j.cattod.2011.04.003

Shen, Y., and Yoshikawa, K. (2013). "Recent progresses in catalytic tar elimination during biomass gasification or pyrolysis-A review," Renew. Sust. Energ. Rev. 21, 371-392. DOI: 10.1016/j.rser.2012.12.062

Shen, Y., Zhao, P., Shao, Q., Ma, D., Takahashi, F., and Yoshikawa, K. (2014). "In-situ catalytic conversion of tar using rice husk char-supported nickel-iron catalysts for biomass pyrolysis/gasification," Appl. Catal. B-Environ. 152-153, 140-151. DOI: 10.1016/j.apcatb.2014.01.032

Wu, C., Wang, L., Williams, P. T., Shi, J., and Huang, J. (2011). "Hydrogen production from biomass gasification with Ni/MCM-41 catalysts: Influence of Ni content," Appl. Catal. B-Environ. 108-109, 6-13. DOI: 10.1016/j.apcatb.2011.07.023

Xie, Y., Su, Y., Wang, P., Zhang, S., and Xiong, Y. (2018). "In-situ catalytic conversion of tar from biomass gasification over carbon nanofibers- supported Fe-Ni bimetallic catalysts," Fuel Process. Technol. 182, 77-87. DOI: 10.1016/j.fuproc.2018.10.019

Xu, X., Zhao, B., Sun, M., Chen, X., Zhang, M., Li, H., and Xu, S. (2017). "Co-pyrolysis characteristics of municipal sewage sludge and hazelnut shell by TG-DTG-MS and residue analysis," Waste Manage. 62, 91-100. DOI: 10.1016/j.wasman.2017.02.012 
Yang, Y., Zhu, J., Zhu, G., Yang, L., and Zhu, Y. (2018). "The effect of high temperature on syngas production by immediate pyrolysis of wet sewage sludge with sawdust," $J$. Therm. Anal. Calorim. 132(3), 1783-1794. DOI: 10.1007/s10973-018-7143-9

Zhang, Z., Hu, X., Zhang, L., Yang, Y., Li, Q., Fan, H., Liu, Q., Wei, T., and Li, C.-Z. (2019). "Steam reforming of guaiacol over Ni/Al ${ }_{2} \mathrm{O}_{3}$ and Ni/SBA-15: Impacts of support on catalytic behaviors of nickel and properties of coke," Fuel Process. Technol. 191, 138-151. DOI: 10.1016/j.fuproc.2019.04.001

Zhang, Z., Liu, L., Shen, B., and Wu, C. (2018). "Preparation, modification and development of Ni-based catalysts for catalytic reforming of tar produced from biomass gasification," Renew. Sust. Energ. Rev. 94, 1086-1109. DOI: 10.1016/j.rser.2018.07.010

Zhao, M., Florin, N. H., and Harris, A. T. (2009). "The influence of supported Ni catalysts on the product gas distribution and $\mathrm{H}_{2}$ yield during cellulose pyrolysis," Appl. Catal. B-Environ. 92(1-2), 185-193. DOI: 10.1016/j.apcatb.2009.07.011

Zhou, Y., Wang, W., Sun, J., Fu, L., Song, Z., Zhao, X., and Mao, Y. (2017). "Microwave-induced electrical discharge of metal strips for the degradation of biomass tar," Energy 126, 42-52. DOI: 10.1016/j.energy.2017.03.008

Article submitted: October 31, 2019; Peer review completed: December 31, 2020; Revised version received: January 11, 2020; Accepted: January 12, 2020; Published: January 24, 2020.

DOI: $10.15376 /$ biores.15.1.1716-1731 